\title{
High-latitude ion temperature climatology during the International Polar Year 2007-2008
}

\author{
Y. Yamazaki ${ }^{1, *}$, M.J. Kosch ${ }^{1,2,3}$, Y. Ogawa ${ }^{4,5}$, and D.R. Themens ${ }^{6}$ \\ 1 Department of Physics, Lancaster University, Lancaster LA1 4YB, UK \\ *Corresponding author: y.yamazaki@lancaster.ac.uk \\ 2 South African National Space Agency, Hermanus 7200, South Africa \\ 3 University of the Western Cape, Bellville 7535, South Africa \\ 4 National Institute of Polar Research, Tachikawa 190-8518, Japan \\ 5 Department of Polar Science, School of Multidisciplinary Sciences, SOKENDAI (Graduate University for Advanced Studies), \\ Tachikawa 190-8518, Japan \\ 6 Department of Physics, University of New Brunswick, Fredericton, New Brunswick E3B 5A3, Canada
}

Received 5 March 2016 / Accepted 30 August 2016

\begin{abstract}
This article presents the results of an ion temperature climatology study that examined ionospheric measurements from the European Incoherent SCATter (EISCAT) Svalbard Radar (ESR: 78.2 ${ }^{\circ} \mathrm{N}, 16.0^{\circ} \mathrm{E}$ ) and the Poker Flat Incoherent Scatter Radar (PFISR: $65.1^{\circ} \mathrm{N}, 212.6^{\circ} \mathrm{E}$ ) during the year-long campaign of the International Polar Year (IPY) from March 2007 to February 2008. These observations were compared with those of the Thermosphere Ionosphere Electrodynamics General Circulation Model (TIE-GCM), as well as the International Reference Ionosphere 2012 (IRI-2012). Fairly close agreement was found between the observations and TIE-GCM results. Numerical experiments revealed that the daily variation in the high-latitude ion temperature, about 100-200 K, is mainly due to ion frictional heating. The ion temperature was found to increase in response to elevated geomagnetic activity at both ESR and PFISR, which is consistent with the findings of previous studies. At ESR, a strong response occurred during the daytime, which was interpreted as a result of dayside-cusp heating. Neither TIE-GCM nor IRI-2012 reproduced the strong geomagnetic activity response at ESR, underscoring the need for improvement in both models at polar latitudes.
\end{abstract}

Key words. Ion temperature - EISCAT Svalbard radar - Poker Flat Incoherent Scatter Radar - TIE-GCM - IRI - International Polar Year

\section{Introduction}

Incoherent scatter radars are very powerful remote-sensing tools for upper atmospheric studies. The radars transmit radio waves toward the sky and observe the backscatter of the waves caused by random fluctuations of ionospheric plasma. Ionospheric quantities can be derived from the received radar spectrum (Evans 1969). This is done by fitting a theoretical spectrum to the radar spectrum and finding the most likely combination of $T_{\mathrm{i}} / m_{\mathrm{i}}$ (the ratio of ion temperature to ion mass), $T_{\mathrm{e}} / T_{\mathrm{i}}$ (the ratio of electron temperature to ion temperature), ion velocity $v_{\mathrm{i}}$ in the line-of-sight direction, and electron density $n_{\mathrm{e}}$. Thus for assumed $m_{\mathrm{i}}$, altitude profiles of $T_{\mathrm{i}}$ and $T_{\mathrm{e}}$ can be determined, along with those for $v_{\mathrm{i}}$ and $n_{\mathrm{e}}$. These ionospheric parameters provide insight into thermal and dynamical states of the upper atmosphere.

The International Polar Year (IPY) is an international science program that aims to advance our understanding of the Earth's polar region. The first and second IPY occurred in 1882-1883 and 1932-1933, respectively. The third IPY took place from March 2007 to March 2009 (Allison et al. 2007). The IPY period coincided with an unusually quiet solar minimum between solar cycles 23 and 24 (Russell et al. 2010), which led to the coldest thermosphere ever recorded (Solomon et al. 2010; Emmert et al. 2014). One of the major contributions of the upper atmosphere research community to the IPY was the unprecedented year-long observations by two incoherent scatter radars in the polar region (Sojka et al. 2007). One is the European Incoherent SCATter (EISCAT) Svalbard Radar (ESR, $78.2^{\circ} \mathrm{N}, 16.0^{\circ} \mathrm{E}$ ) and the other is the Poker Flat Incoherent Scatter Radar (PFISR, $65.1^{\circ} \mathrm{N}$, $212.6^{\circ} \mathrm{E}$. The campaign successfully achieved nearly $24 / 7$ continuous observations at the two sites from March 2007 to February 2008 (Sojka et al. 2011). The IPY data have been explored by various researchers for a variety of purposes (Richards et al. 2009; Blelly et al. 2010; Zhang et al. 2010; Ogawa et al. 2011; Vlasov et al. 2011; Vickers et al. 2013).

The present study focused on the ion temperature climatology in the polar region during the IPY. Ion temperature can be used as a diagnostic marker for the energy state of ionospheric plasma, in which ions exchange energy with both electrons and neutrals. Among earlier studies, particularly relevant works include those by Sojka et al. (2011) and Fujiwara et al. (2012). Sojka et al. (2011) presented the ion temperature climatology at $300 \mathrm{~km}$ using ESR and PFISR measurements during the IPY. They compared the observations with the International Reference Ionosphere 2007 (IRI-2007) (Bilitza \& Reinisch 2008) and found that ion temperatures from the IRI-2007 were about 200-300 K higher than their observations. Sojka et al. (2011) also compared the observations with the neutral temperature from the empirical NRLMSISE-00 atmosphere model (Picone et al. 2002). Agreement was very 
Table 1. Data set.

\begin{tabular}{|c|c|c|c|c|c|c|c|}
\hline & ESR (hrs) & PFISR (hrs) & $B_{z}(\mathrm{nT})$ & $B_{y}(\mathrm{nT})$ & $V_{x}(\mathrm{~m} / \mathrm{s})$ & $N_{\mathrm{p}}(/ \mathrm{cc})$ & $a p(\mathrm{nT})$ \\
\hline Winter $(K p<1)$ & $24.7 \times 24$ & $41.0 \times 24$ & $0.5 \pm 0.1$ & $0.1 \pm 0.3$ & $385 \pm 14$ & $5.6 \pm 0.4$ & $1.6 \pm 0.3$ \\
\hline Equinox $(K p<1)$ & $35.9 \times 24$ & $42.4 \times 24$ & $0.6 \pm 0.2$ & $0.1 \pm 0.2$ & $359 \pm 5$ & $5.9 \pm 0.4$ & $1.7 \pm 0.2$ \\
\hline Summer $(K p \leq 1)$ & $37.7 \times 24$ & $48.0 \times 24$ & $0.4 \pm 0.2$ & $-0.2 \pm 0.3$ & $375 \pm 5$ & $5.0 \pm 0.2$ & $2.1 \pm 0.2$ \\
\hline Winter $(2 \leq K p<4)$ & $28.7 \times 24$ & $46.4 \times 24$ & $0.0 \pm 0.3$ & $0.3 \pm 0.3$ & $572 \pm 22$ & $4.2 \pm 0.6$ & $13.2 \pm 0.6$ \\
\hline Equinox $(2 \leq K p<4)$ & $30.6 \times 24$ & $40.6 \times 24$ & $-0.1 \pm 0.4$ & $-0.5 \pm 0.3$ & $515 \pm 15$ & $5.9 \pm 0.6$ & $12.7 \pm 1.0$ \\
\hline Summer $(2 \leq K p \leq 4)$ & $23.4 \times 24$ & $30.6 \times 24$ & $-0.3 \pm 0.4$ & $-0.5 \pm 0.7$ & $505 \pm 15$ & $7.2 \pm 1.7$ & $12.2 \pm 0.9$ \\
\hline
\end{tabular}

close for PFISR, especially when geomagnetic activity was very low, suggesting that ionospheric ions were approximately in thermal equilibrium with neutrals. ESR results, however, showed different patterns of the daily variation compared to the NRLMSISE-00 neutral temperature. Fujiwara et al. (2012) also pointed out that the discrepancy between quiettime ESR ion temperature and NRLMSISE-00 neutral temperature can be up to $250 \mathrm{~K}$, arguing that there are significant heat sources that are not taken into account. They attempted to identify the heat source using the general circulation model introduced by Miyoshi \& Fujiwara (2003), but had difficulties in reproducing the observations, as their model did not include a self-consistent ionosphere.

In this study, we used the Thermosphere Ionosphere General Circulation Model (TIE-GCM), which considers mutual coupling of the thermosphere and ionosphere (Richmond et al. 1992; Qian et al. 2014). This provided us with the first opportunity to evaluate various physical processes contributing to the ion temperature in the polar region, such as electron heating and ion-neutral frictional heating. We also compared the observations with the 2012 version of the International Reference Ionosphere, IRI-2012 (Bilitza et al. 2014). This provides insight into the performance of the "theoretical" TIE-GCM relative to the "observation-based" IRI model.

\section{Data and models}

\subsection{Incoherent scatter radars}

The EISCAT Svalbard Radar is located at $78.2^{\circ} \mathrm{N}, 16.0^{\circ} \mathrm{E}$, in Longyearbyen, Svalbard, Norway. Magnetic latitude of the radar site is approximately $75^{\circ}$, and thus it is usually in the northern polar cap. The year-long operation during the IPY was conducted with the 42-m dish antenna, which is fixed in the field-aligned position. For the present study, the radar spectra were integrated to $5 \mathrm{~min}$, and the plasma parameters $T_{\mathrm{i}}, T_{\mathrm{e}}, N_{\mathrm{e}}$, and $v_{\mathrm{i}}$ were derived conventionally using the Grand Unified Incoherent Scatter Design and Analysis Package (GUISDAP) (Lehtinen \& Huuskonen 1996). We used ion temperature data at 125,275 , and $350 \mathrm{~km}$. Observational errors rapidly increase below $125 \mathrm{~km}$ and above $350 \mathrm{~km}$ because of the low signal-to-noise ratio. In addition, altitudes around the ion composition transition of $\sim 200 \mathrm{~km}$ were avoided, since the estimation of ion temperature often becomes inaccurate (Blelly et al. 2010; Zettergren et al. 2011; Oliver et al. 2014).

The Poker Flat Incoherent Scatter Radar is located at the Poker Flat Research Range $\left(65.1^{\circ} \mathrm{N}, 212.6^{\circ} \mathrm{E}\right)$ near Fairbanks, Alaska. The radar site is mostly in the auroral region, with magnetic latitude being approximately $65^{\circ}$. The IPY mode operates with a low-duty cycle $(\sim 1 \%)$ for the purpose of background ionosphere monitoring. We used the measurements from the field-aligned direction. The ion temperature was derived at the same altitudes as the ESR data, i.e., 125,275 , and $350 \mathrm{~km}$. Thirty-min time integration was used to obtain sufficient signal-to-noise ratio. Although this study focuses on the IPY period from March 2007 to February 2008, the IPY mode was actually run at PFISR for the entire operational life of the system (2007 to present).

The ion temperature data were separated into three seasonal groups: summer (May-August), equinox (March-April, September-October), and winter (November-February). The data were also divided into two groups according to geomagnetic activity: very quiet conditions $(K p<1)$ and moderately active conditions $(2 \leq K p<4)$. Table 1 shows the amount of data in each data group, along with the average solar wind parameters, interplanetary magnetic field (IMF) $B_{y}$ and $B_{z}$, solar wind speed $V_{x}$, and solar wind density $N_{\mathrm{p}}$. The last row shows the average value of the geomagnetic activity index $a p$. The solar wind data were obtained from the OMNI 2 data set described by King \& Papitashvili (2005).

It can be seen in Table 1 that the distribution of the radar data is more or less uniform. Each data group covers $\sim 30$ days for ESR and $\sim 40$ days for PFISR. Although the IPY took place during the solar minimum, the high-latitude ionosphere remained under the influence of disturbances associated with the passage of solar wind corotating interaction regions (CIRs) (Sojka et al. 2009). Generally, CIR events are accompanied by elevated solar wind speeds and geomagnetic activity (Tsurutani et al. 2006). According to Sojka et al. (2009), there were 55 CIR events during the IPY. Table 1 also shows that our data binning, based on the geomagnetic activity index $K p$, separates the data for relatively high and low solar wind speeds.

\subsection{TIE-GCM}

The TIE-GCM is a first-principles general circulation model of the upper atmosphere, developed at the National Center for Atmospheric Research (NCAR) (Richmond et al. 1992; Qian et al. 2014). It solves continuity, momentum, and energy equations for the coupled ionosphere-thermosphere system. The horizontal resolution of the model is $5^{\circ} \times 5^{\circ}$ in latitude and longitude, and the vertical resolution is half a scale height. The lower boundary of the model is at approximately $96 \mathrm{~km}$, and the upper boundary is at about $450 \mathrm{~km}$ in our simulations for solar minimum conditions. The electrodynamics of the TIE-GCM is calculated in the Magnetic Apex coordinate system (Richmond 1995) with the International Geomagnetic Reference Field (Finlay et al. 2010). We used version 1.95 of the TIE-GCM.

The model requires the day of year DoY and solar activity index $\mathrm{F}_{10.7}$ as inputs. Our simulations were run with 
Winter

(a)

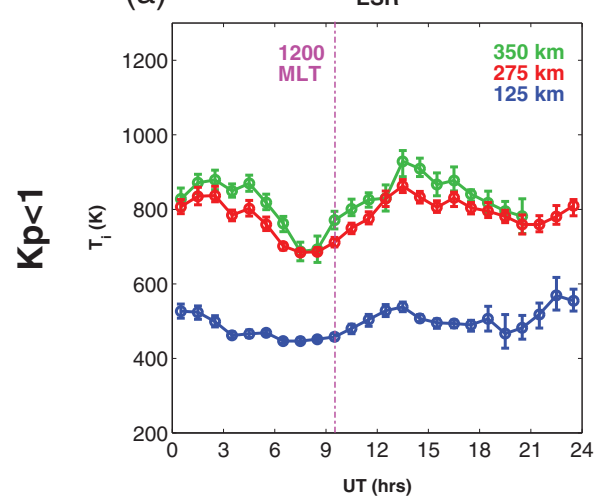

(d)
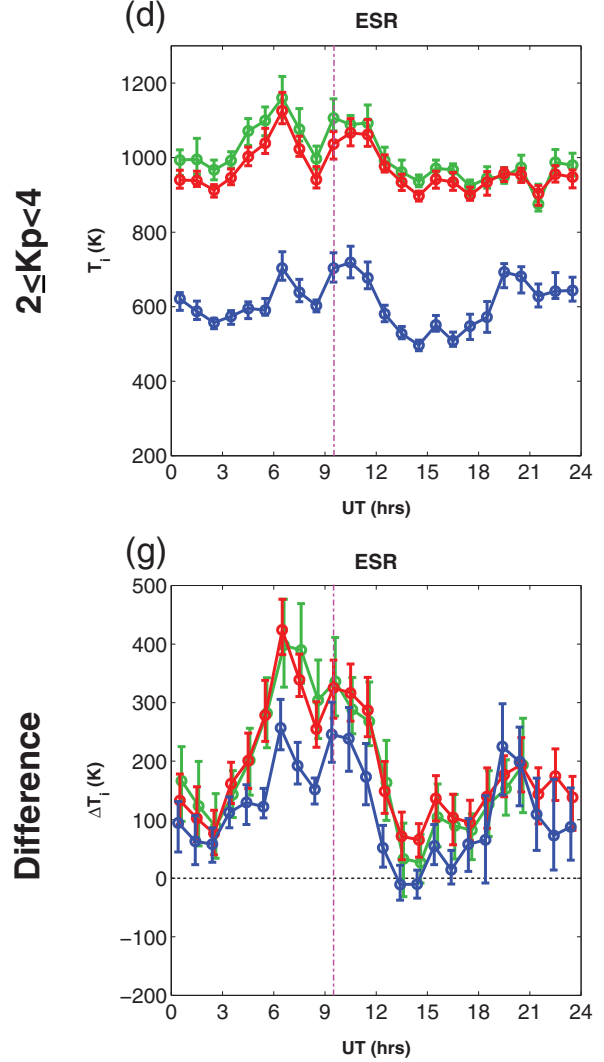

Equinox

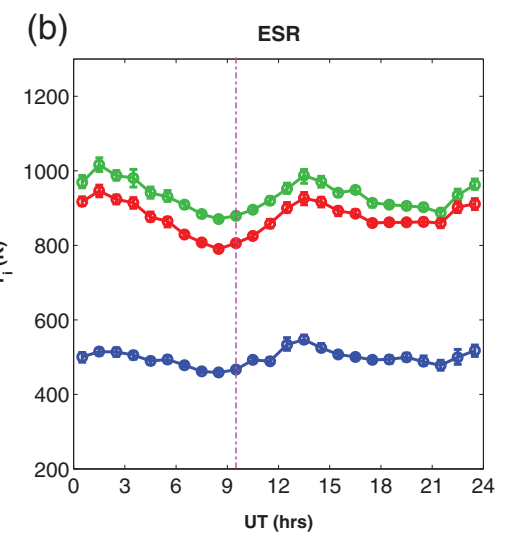

(e)

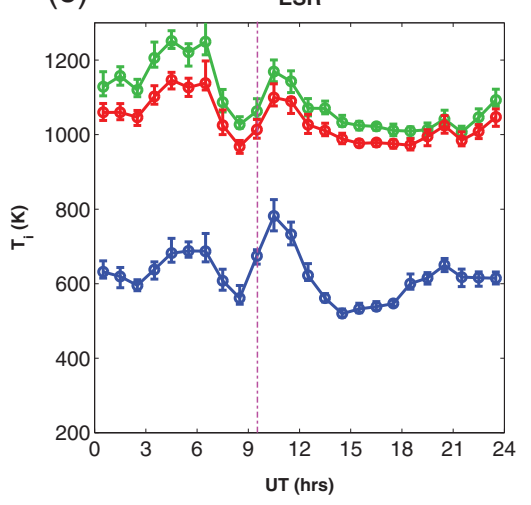

(h)

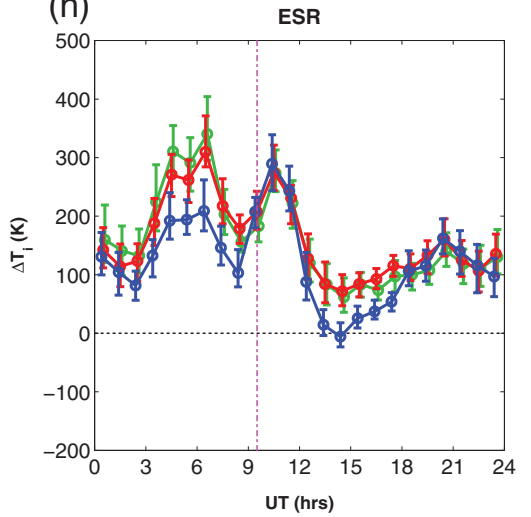

Summer

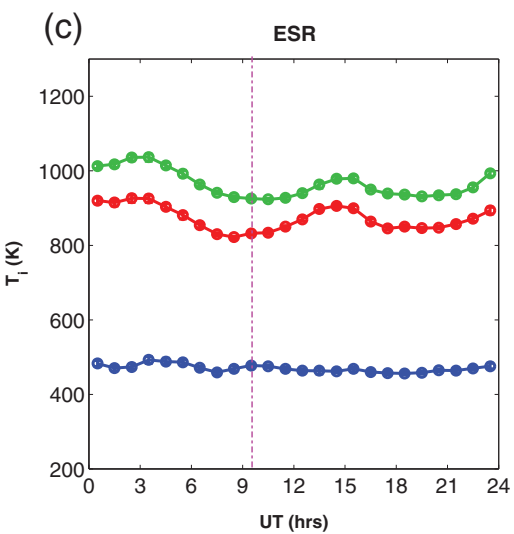

(f)
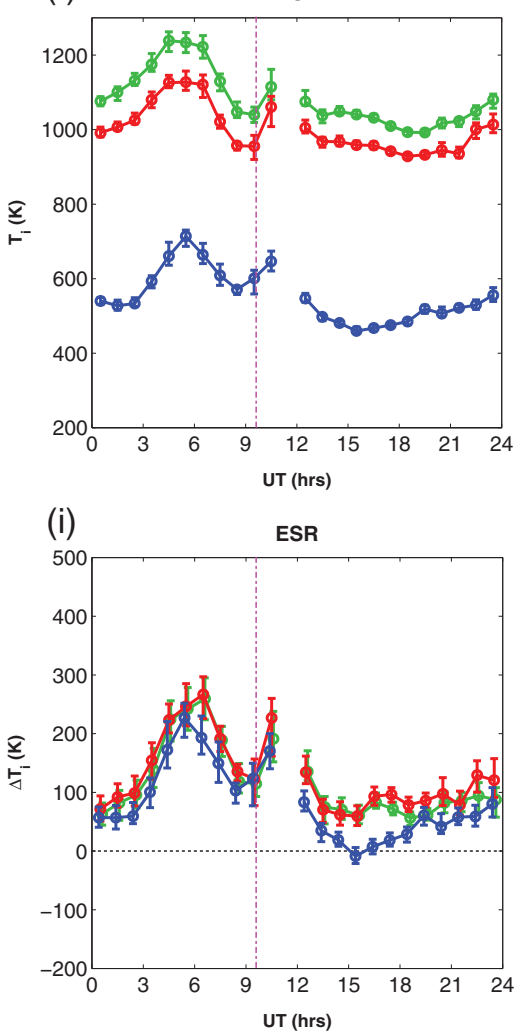

Fig. 1. The ion temperature climatology at ESR. Panels $(\mathrm{a}-\mathrm{c})$ are for the very quiet conditions $(K p<1)$ and Panels (d-f) are for the moderately active conditions $(2 \leq K p<4)$. Panels $(\mathrm{g}-\mathrm{i})$ show the differences between the results for the moderately active conditions and very quiet conditions. Panels (a), (d), and (g) are for the winter; Panels (b), (e), and (h) are for the equinox; and Panels (c), (f), and (i) are for the summer. In each panel, the green line indicates the results at $350 \mathrm{~km}$, the red line those at $275 \mathrm{~km}$, and the blue those at $125 \mathrm{~km}$. The error bars indicate the $95 \%$ confidence interval. The magnetic local time noon is indicated by the vertical magenta line.

$\mathrm{DoY}=172$ for summer, $\mathrm{DoY}=80$ for equinox, and $\mathrm{DoY}=355$ for winter. Since variations in $\mathrm{F}_{10.7}$ are small during the solar minimum, we used a fixed value for the solar input, $\mathrm{F}_{10.7}=72 \mathrm{sfu}$ (solar flux unit, $10^{-22} \mathrm{Wm}^{-2} \mathrm{~Hz}^{-1}$ ), which is the average value for the IPY period. The amplitude and phase of the migrating diurnal and semidiurnal tides were specified at the lower boundary of the model, $\sim 96 \mathrm{~km}$, using the Global Scale Wave Model (Hagan \& Forbes 2002, 2003). These lower-boundary tides imitate the effect that upward-propagating tides from the lower atmosphere exert on the ionosphere-thermosphere system (Yamazaki \& Richmond 2013). Electric fields above $45^{\circ}$ magnetic latitudes were specified using an empirical model by Weimer (2005), which mimics the impact of the electric fields imposed from the magnetosphere. The solar wind parameters in Table 1 were used as inputs for the Weimer model. All the simulations were run until the diurnally reproducible state was established.

\subsection{IRI-2012}

IRI-2012 is the latest version of the International Reference Ionosphere (Bilitza et al. 2014), a data-based empirical model. The IRI ion temperature at $430 \mathrm{~km}$ is derived from a model described by Bilitza (1981), which is based on incoherent scatter radar data from Millstone Hill (1972-1975), Arecibo (1966-1972), and Jicamarca (1966-1969), as well as global 

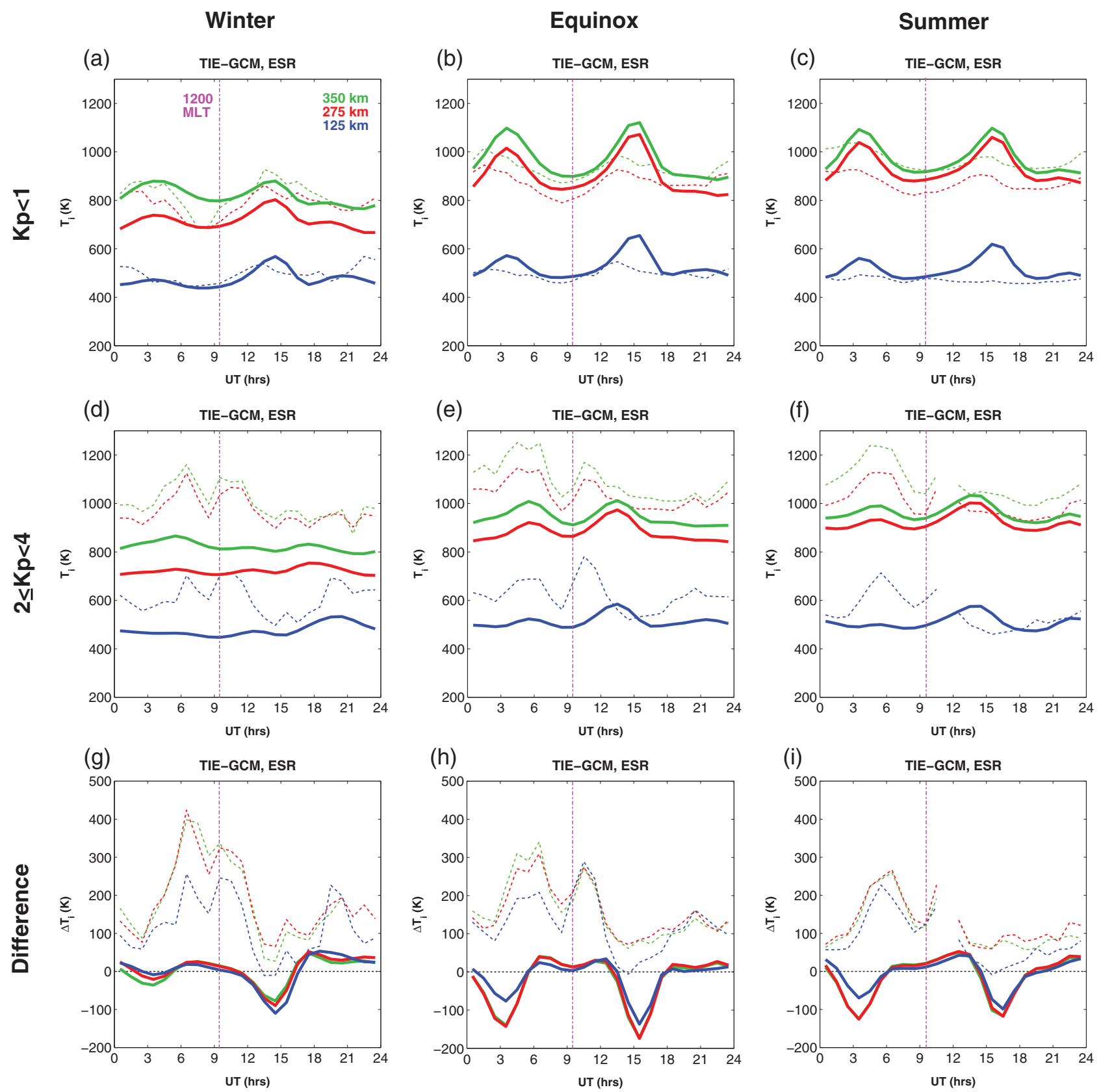

Fig. 2. The same variables as presented in Figure 1 for the TIE-GCM results at the ESR location. The observational results are also indicated by thin dashed lines.

satellite measurements by AEROS-A (1972-1973) and AEROS-B (1974-1975). The model by Bilitza (1981) takes into account the dependence of the ion temperature on latitude and solar time but does not consider the dependence on season, geomagnetic activity, or solar activity. The height dependence of the IRI ion temperature is parameterized in the way described by Bilitza (1990). Below $120 \mathrm{~km}$, the ion temperature of IRI-2012 always equals the neutral temperature from the NRLMSISE-00 model (Picone et al. 2002). The ion temperature of the IRI-2012 can vary with the season, geomagnetic activity, and solar activity, but only indirectly via the NRLMSISE-00 model's dependence on these characteristics. IRI-2012 was run for the periods corresponding to the radar data but with fixed solar activity indices according to the average value during the IPY; $\mathrm{F}_{10.7}=72, \mathrm{Rz} 12=6.7$, and $\mathrm{IG} 12=-0.89$, where Rz12 is the 12 -month running mean of the sunspot number and IG12 is the 12-month running mean of the Global Ionospheric-effective solar index IG. This was to ensure that the difference in the results for $K p<1$ and $2 \leq K p<4$ resulted from geomagnetic activity, and not from small perturbations in solar activity.

\section{Results and discussion}

\subsection{ESR}

The ESR ion temperature climatology is presented in Figure 1: (a), (d), and (g) for winter; (b), (e), and (h) for equinox; and (c), (f), and (i) for summer. In each panel, the various colors indicate different heights: blue for $125 \mathrm{~km}$, red for $275 \mathrm{~km}$, and green for $350 \mathrm{~km}$. The solid lines indicate the median value for each hour, and the error bars represent the $95 \%$ 
Y. Yamazaki et al.: Ion temperature climatology
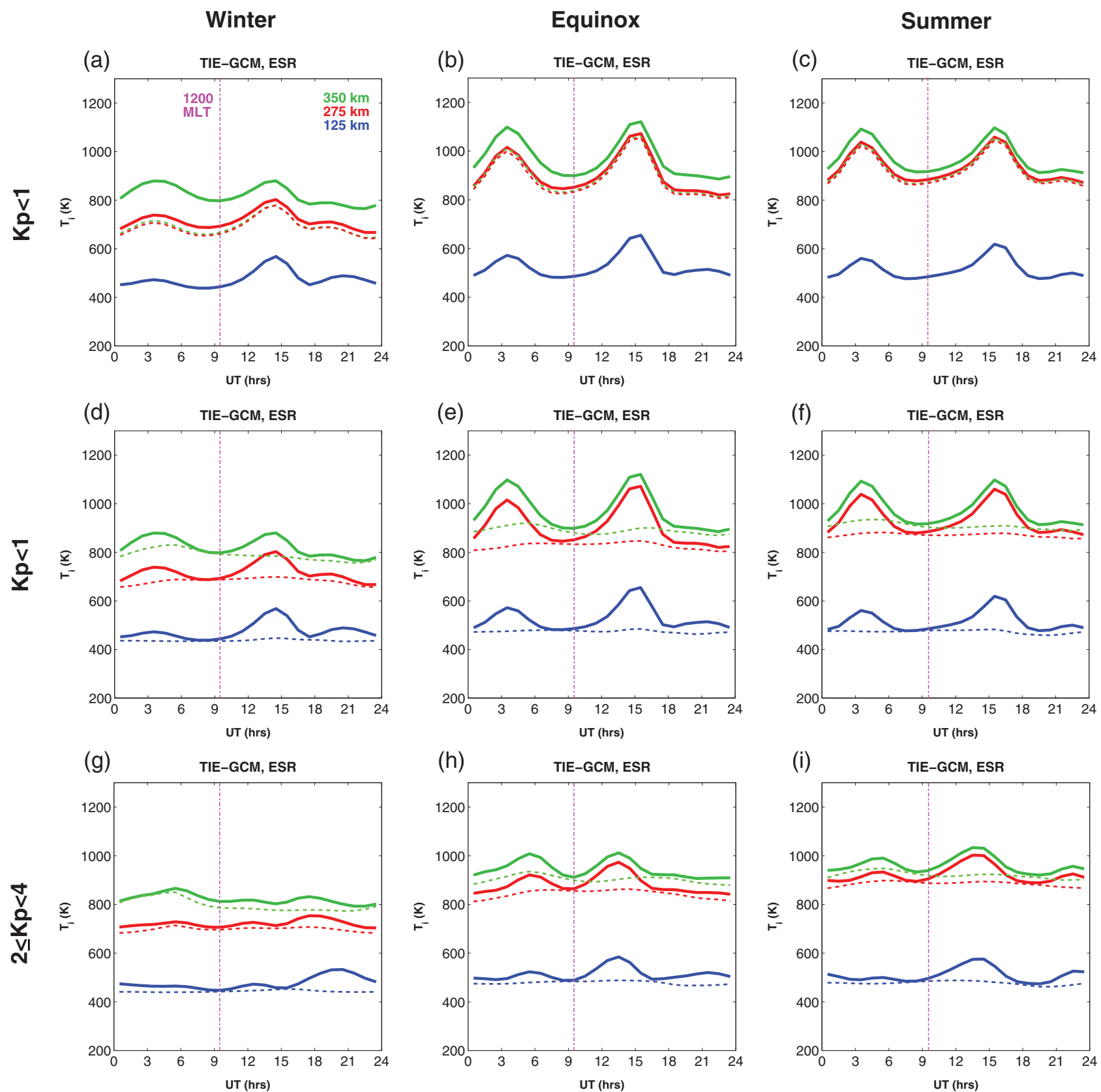

Fig. 3. The results of TIE-GCM numerical experiments. In Panels $(a-c)$, the solid lines show the same variables as Panels (a-c) of Figure 2, while the dashed lines show the corresponding results calculated using Eq. (2) that neglects the effect of electron heating. In Panels (d-i), the solid lines show the same variables as Panels $(a-f)$ of Figure 2, while the dashed lines show the corresponding results calculated using Eq. (3) that neglects the effect of ion-neutral frictional heating. Of note, the dashed blue line in Panels $(\mathrm{a}-\mathrm{c})$ closely overlaps with the solid blue line. Also, the dashed green line in Panels $(\mathrm{a}-\mathrm{c})$ is partly hidden by the red lines.

confidence interval estimated by the bootstrap method (Efron 1981). The results were omitted if the available data were less than $12 \mathrm{~h}$ in total. The top panels are for $K p<1$, and the middle panels are for $2 \leq K p<4$. The bottom panels show the difference in the results for $K p<1$ and $2 \leq K p<4$, representing the response of the ion temperature to geomagnetic activity. The uncertainty is smallest during the summer when the highest signal-to-noise ratio is achieved due to high plasma density. For both $K p<1$ and $2 \leq K p<4$, the ion temperature increased with increasing height. The ion temperature tends to increase from the winter to summer, especially at greater heights. This is probably due to elevated solar heating during the summer. These results on the seasonal and height dependence of $T_{\mathrm{i}}$ are consistent with the ion temperature climatology presented earlier by Remick (2006), who also used ESR data but for the solar maximum period for 1998-2001.

The daily variation of the quiet-time ion temperature was dominated by the semidiurnal variation with local maxima around 1-3 UT and 13-15 UT (Figs. 1a-1c). A similar daily variation was reported by Sojka et al. (2011) at $300 \mathrm{~km}$. Sojka et al. (2011) stated that the two peaks correspond to the noon and midnight magnetic local time (MLT). However, MLT at the ESR location is approximately $2.5 \mathrm{hr}$ ahead of UT, so that 2 UT and 14 UT correspond roughly to 4.5 MLT and 16.5 MLT, respectively. Therefore, enhanced ion temperature occurs around predawn and pre-dusk MLT hours, rather than 

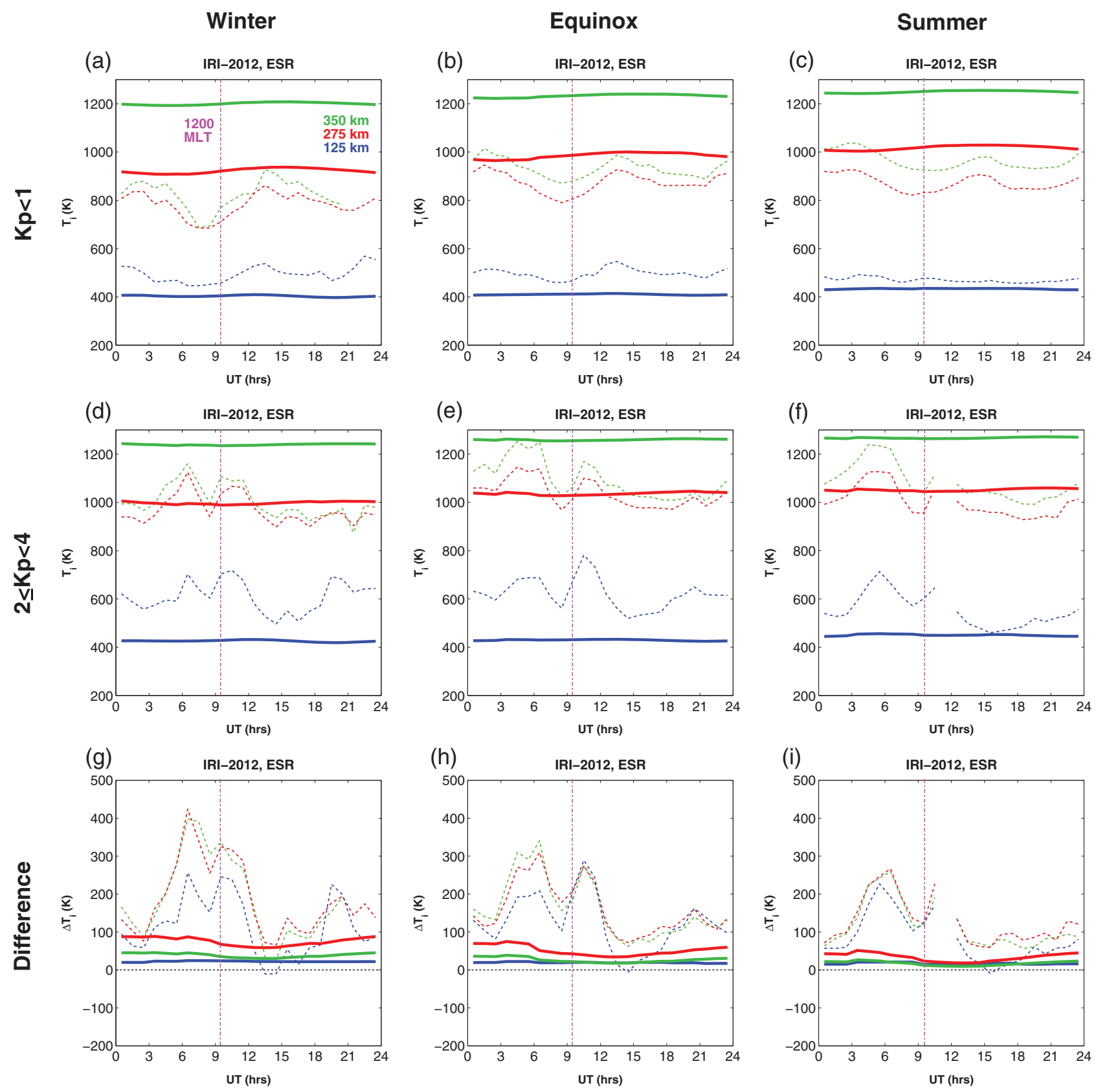

Fig. 4. The same variables as presented in Figure 1 for the IRI-2012 results at the ESR location. The observational results are also indicated by thin dashed lines.

noon and midnight. The pattern of the daily variation depends on geomagnetic activity. For $2 \leq K p<4$, local maxima in the ion temperature occurred around 6 UT and 10 UT (Fig. 1a-1c), closer to the MLT noon in comparison with the $K p<1$ results.

The response of the ESR ion temperature to geomagnetic activity was greater during the daytime than nighttime (Figs. 1g-1i). This may be due to heating in the dayside-cusp region. It has been suggested that the dayside-cusp region is subject to local heating owing to enhanced soft particle precipitation and Poynting flux (Crowley et al. 2010; Zhang et al. 2012; Deng et al. 2013). The dayside-cusp heating creates a bulge of thermospheric mass density, which has been observed from low-earth orbit satellites (Lühr et al. 2004; Rentz \& Lühr 2008).
The response of the ion temperature to geomagnetic activity was also seasonally dependent (Figs. 1g-1i). At 275 and $350 \mathrm{~km}$, the maximum response occurred in the winter and the minimum response occurred in the summer. A similar seasonal change has been reported for the response of the cusp region density to geomagnetic activity (Yamazaki et al. 2015a), but the mechanism is yet to be understood. Joule heating varies with Pedersen conductivity and is expected to be greater during the summer than winter because of higher ionization rates (Weimer 2005).

Figure 2 shows the TIE-GCM results for the ion temperature climatology at the ESR location. The model-data agreement is fairly close for the $K p<1$ condition (Figs. 2a-2c). The TIE-GCM reproduces the dependence of the ion temperature on altitude and season fairly well. The model also 

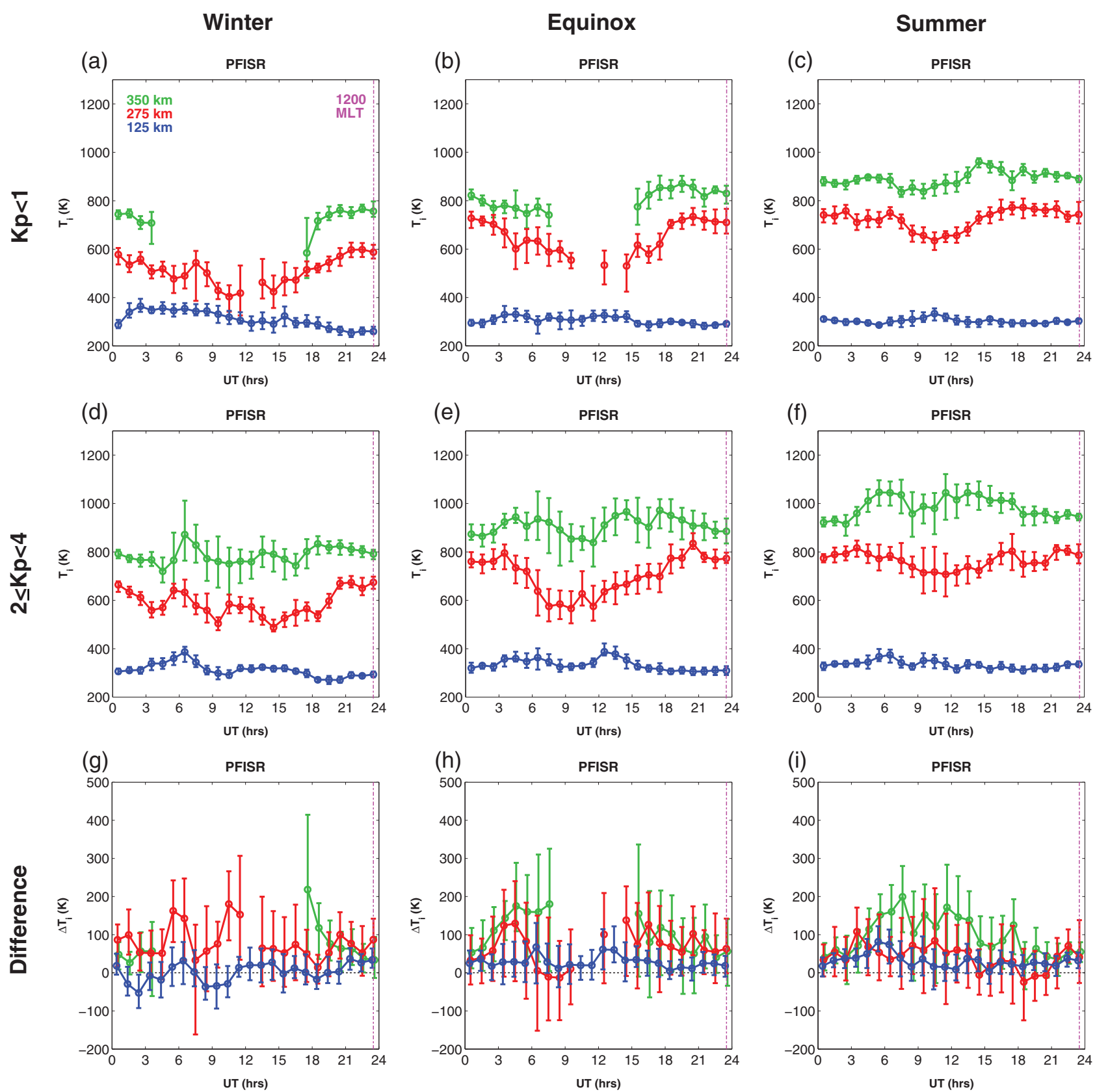

Fig. 5. The same variables as presented in Figure 1 for the results at PFISR.

reproduces the semidiurnal variation of the ion temperature. However, the model tends to overestimate the amplitude of the daily variation. For the moderately active geomagnetic condition, $2 \leq K p<4$, the TIE-GCM underestimates the ion temperature by $\sim 100-300 \mathrm{~K}$ (Figs. 2d-2f). Indeed, the TIE-GCM ion temperature decreases around 3 and 15 UT in response to geomagnetic activity (Figs. $2 \mathrm{~g}-2 \mathrm{i}$ ). The expansion of the polar cap is predicted to cause the region of strong Joule heating to move equatorward, away from the ESR site. The observations do not show such a negative response to geomagnetic activity. Nonetheless, the observations and model agree in that the minimum response occurs around 3 and $15 \mathrm{UT}$. The weak geomagnetic activity response of the TIE-GCM ion temperature suggests that there is a heating mechanism missing from the model. Earlier versions of the TIE-GCM often underestimated high-latitude Joule heating because of the lack of electric field variability
(Deng et al. 2009). Version 1.95 of the TIE-GCM artificially increases the Joule heating rate by a factor of 1.5 to compensate for weak heating. We suspect that the underestimation of the TIE-GCM response to geomagnetic activity is due to the lack of heating in the dayside-cusp region. TIE-GCM version 1.95 does not include any mechanism associated with local heating in the dayside-cusp region. The neutral temperature in the empirical NRLMSISE-00 model also shows a similarly weak response to geomagnetic activity (not shown here). In addition, the NRLMSISE-00 model does not reproduce the geomagnetic activity response in the dayside-cusp region (Liu et al. 2005; Yamazaki et al. 2015b).

Although the TIE-GCM underestimates the response of the ion temperature to geomagnetic activity, the model often reproduces the correct pattern of the daily variation for both $K p<1$ and $2 \leq K p<4$ conditions. In either case, the ion temperature shows two maxima in the course of a day. For $K p<1$, the two 

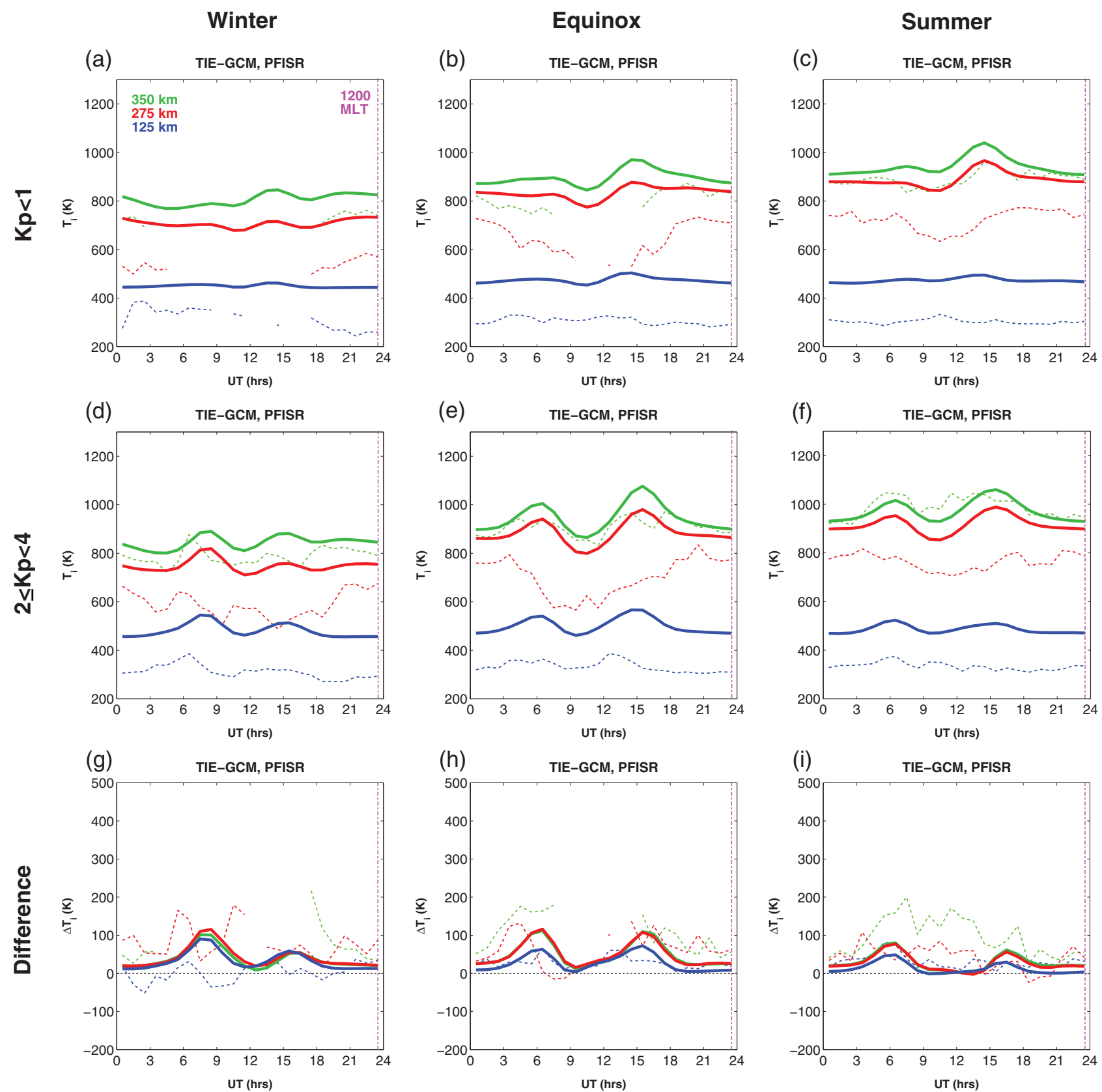

Fig. 6. The same variables as presented in Figure 2 for the results at PFISR.

maxima are approximately $12 \mathrm{~h}$ apart, and for $2 \leq K p<4$, they are closer to the MLT noon. In order to provide physical insight into these observations, we looked into the model equation governing ion temperature. Ion temperature in the TIEGCM is determined by a heat balance in which ions are heated by the electrons and by ion-neutral frictional heating and are cooled by collisions with neutrals. That is,

$$
\begin{gathered}
L_{\mathrm{ei}}\left(T_{\mathrm{e}}-T_{\mathrm{i}}\right)+\rho Q_{\mathrm{J}}=L_{\mathrm{in}}\left(T_{\mathrm{i}}-T_{\mathrm{n}}\right), \text { or } \\
T_{\mathrm{i}}=\frac{L_{\mathrm{ei}} T_{\mathrm{e}}+L_{\mathrm{in}} T_{\mathrm{n}}+\rho Q_{\mathrm{J}}}{L_{\mathrm{ei}}+L_{\mathrm{in}}}
\end{gathered}
$$

where $L_{\mathrm{ei}}$ is the electron-ion energy transfer rate, $\rho$ is mass density, $Q_{\mathrm{J}}$ is the ion-neutral frictional heating rate, $L_{\text {in }}$ is the ion-neutral energy transfer rate, and $T_{\mathrm{n}}$ is the neutral temperature. The calculation formulae for $L_{\mathrm{ei}}$ and $L_{\mathrm{in}}$ can be found in the Appendix. The electron temperature $T_{\mathrm{e}}$ is computed in the TIE-GCM based on an energy conservation equation; see Lei et al. (2007) for more information on the derivation of $T_{\mathrm{e}}$ in the TIE-GCM.

Fujiwara et al. (2012) assumed that the energy exchange between electrons and ions can be ignored in comparison with the energy exchange between neutrals and ions, which leads to $L_{\mathrm{ei}} \ll L_{\mathrm{in}}$. This removes the electron temperature term from Eq. (1). That is,

$$
T_{\mathrm{i}}=T_{\mathrm{n}}+\frac{\rho}{L_{\mathrm{in}}} Q_{\mathrm{J}}
$$

The validity of this assumption can be evaluated by comparing the ion temperatures calculated with Eqs. (1) and (2). In Figures $3 a-3 c$, the solid and dashed lines indicate the quiet-time ion temperature calculated with Eqs. (1) and (2), respectively. At 125 and $275 \mathrm{~km}$, the results from Eqs. (1) and (2) are nearly identical, and thus the assumption of $L_{\mathrm{ei}} \ll L_{\text {in }}$ is valid to a great extent. At $350 \mathrm{~km}$, Eq. (2) leads 

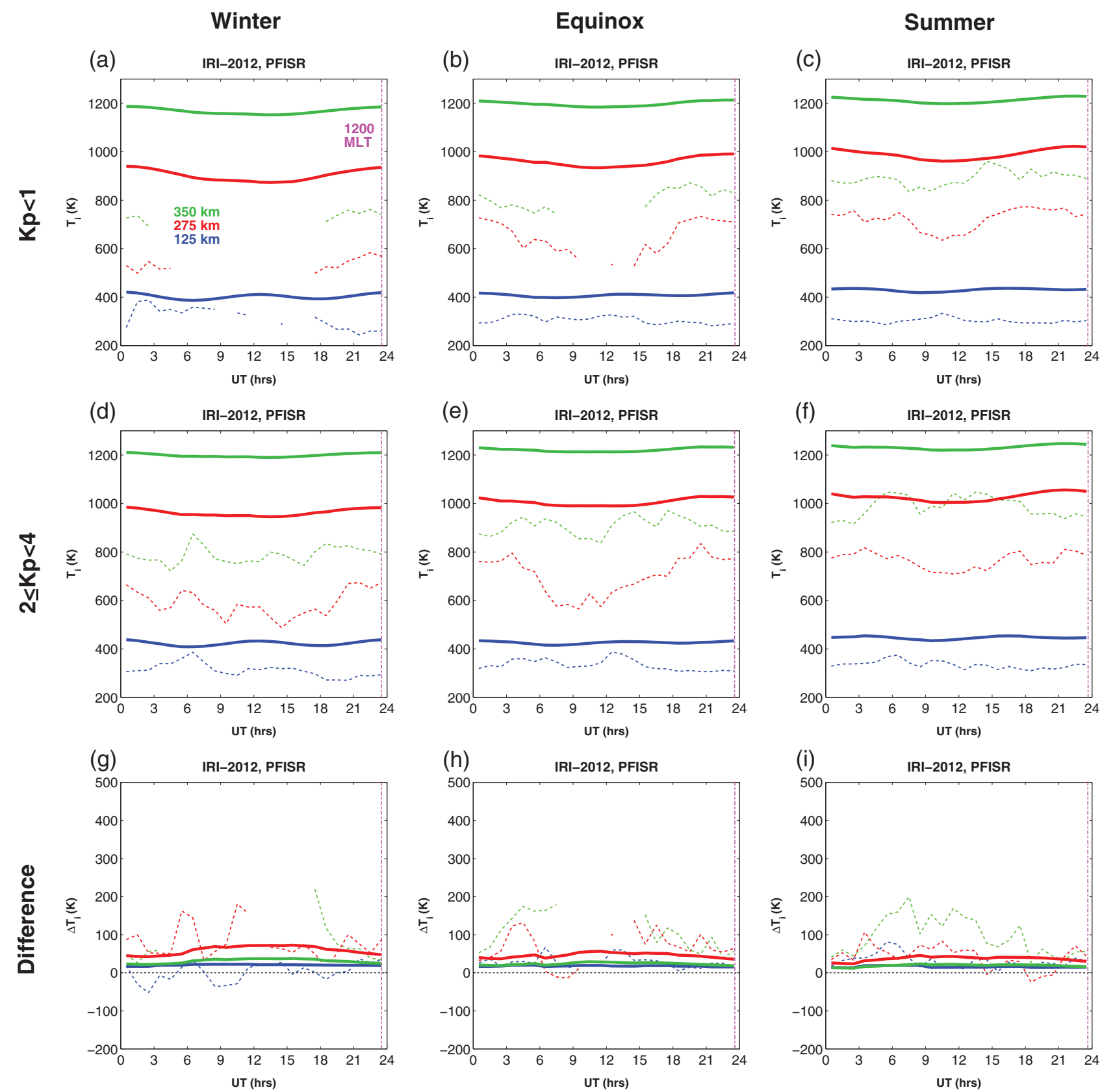

Fig. 7. The same variables as presented in Figure 4 for the results at PFISR.

to the underestimation of the ion temperature by $100-200 \mathrm{~K}$. Of note, when Eq. (2) is used, the ion temperature at $275 \mathrm{~km}$ is nearly equal to the ion temperature at $350 \mathrm{~km}$. This means that the difference in the ion temperature at 275 and $350 \mathrm{~km}$ can be largely attributed to electron heating. We can also observe that the use of Eq. (2) does not affect the pattern of the daily variation. This means that electron heating has little to do with the daily variation of the quiet-time ion temperature.

Next, we calculated the ion temperature with $Q_{\mathrm{J}}=0$ in Eq. (1), so that

$$
T_{\mathrm{i}}=\frac{L_{\mathrm{in}}}{L_{\mathrm{ei}}+L_{\mathrm{in}}} T_{\mathrm{n}}+\frac{L_{\mathrm{ei}}}{L_{\mathrm{ei}}+L_{\mathrm{in}}} T_{\mathrm{e}} .
$$

By comparing the ion temperatures calculated with Eqs. (1) and (3), we can evaluate the effect of ion-neutral frictional heating. The solid and dashed lines in
Figures $3 \mathrm{~d}-3 \mathrm{f}$ show the ion temperature for the $K p<1$ condition calculated with Eqs. (1) and (3), respectively. The results reveal that, when ion-neutral frictional heating is turned off, the daily variation largely disappears. Thus, ion-neutral frictional heating is the main reason for the semidiurnal variation in the quiet-time ion temperature. Although Sojka et al. (2011) assumed that the effect of ion-neutral frictional heating can be ignored under quiet geomagnetic conditions, the TIE-GCM results indicate that ion-neutral frictional heating persists even for $K p<1$ and induces the semidiurnal variation of $100-200 \mathrm{~K}$, which is clearly visible in the data (Figs. 1a-1c). The local maxima in the ion temperature around 1-3 UT and 13-15 UT correspond to the MLTs, when the Joule heating rate is elevated due to a strong electric field (Kosch \& Nielsen 1995; Weimer 2005). Figures $3 g-3 i$ show the same parameters as Figures $3 \mathrm{~d}-3 \mathrm{f}$, but for the $2 \leq K p<4$ condition. Again, 
the effect of ion-neutral frictional heating dominates the daily variation of the ion temperature. The pattern of the daily variation differs from the quiet time because the distribution of Joule heating is different due to the expansion polar cap.

Figure 4 illustrates the ion temperature climatology at the ESR site, predicted by the IRI-2012. The IRI-2012 tends to underestimate the ion temperature at $125 \mathrm{~km}$ and overestimate the ion temperature at $350 \mathrm{~km}$ by $100-200 \mathrm{~K}$. The model fails to reproduce characteristic daily variations for both $K p<1$ and $2 \leq K p<4$. The model also fails to reproduce the strong response of the ion temperature to geomagnetic activity during the daytime. Zhang et al. (2007) found very close agreement between the ion temperatures predicted by the IRI-2000 (Bilitza 2001) and those measured by incoherent scatter radars at Arecibo $\left(18.3^{\circ} \mathrm{N}, 293.2^{\circ} \mathrm{E}\right)$, Millstone Hill $\left(42.6^{\circ} \mathrm{N}\right.$, $288.5^{\circ} \mathrm{E}$ ), and St. Santin $\left(44.6^{\circ} \mathrm{N}, 2.2^{\circ} \mathrm{E}\right.$ ) (see also Zhang \& Holt 2004 and Zhang et al. 2004 for more comparisons at middle latitudes.) Zhang et al. (2007) pointed out that the model-data agreement is not as close for high-latitude radars, including ESR. The poor performance of IRI at high latitudes seems to be directly related to the fact that the ion temperature model of IRI (Bilitza 1981) does not involve data from highlatitude incoherent scatter radars.

\subsection{PFISR}

The ion temperature climatology at PFISR is presented in Figure 5 in the same format as Figure 1. The uncertainty is generally greater at PFISR than at ESR. This is probably due to the fact that PFISR used a low-duty cycle of $\sim 1 \%$, while ESR operated with a high-duty cycle of $\sim 25 \%$ during the IPY. Since the standard error of the mean scales with the square root of the number of independent measurements, the uncertainty in the PFISR climatology is approximately five times greater than that of the ESR results. Nonetheless, the basic characteristics of the ion temperature climatology at PFISR can be seen in Figure 5. The ion temperature at PFISR was generally lower than at ESR (Fig. 1), confirming the results at $300 \mathrm{~km}$ by Sojka et al. (2011). The response of the ion temperature to geomagnetic activity is also weaker at PFISR than at ESR, in agreement with Sojka et al. (2009). The geomagnetic activity response at PFISR tended to be greater during the night than day, which contrasts with the ESR results that show a greater response during the daytime.

A comparison with the TIE-GCM results is presented in Figure 6. The model-data agreement is close at $350 \mathrm{~km}$, but the TIE-GCM systematically overestimates the ion temperature at 125 and $275 \mathrm{~km}$ and the reason for this is not clear. The model reproduces the pattern of the daily variation reasonably well. With increasing geomagnetic activity, the daily variation of the TIE-GCM ion temperature changes from a single-peak pattern for $K p<1$ to a double-peak pattern for $2 \leq K p<4$, which can also be seen in the data during the equinox and summer.

TIE-GCM numerical experiments were conducted, similar to those performed for ESR (see Fig. 3). The results are not shown here as they merely confirm the conclusions obtained from the ESR results. That is, the temperature differences between 275 and $350 \mathrm{~km}$ are mostly due to electron heating, and the pattern of the daily variation is dominated by the effect of ion-neutral frictional heating.

The TIE-GCM results show that the ion temperature at ESR tended to be greater than at PFISR (see Figs. 2 and 6), which is in qualitative agreement with the observations (see Figs. 1 and 5). However, the difference in the ion temperature between the two sites is much more pronounced in the observations. Therefore, the model should be improved to determine the mechanisms underlying the higher ion temperature at ESR than at PFISR.

The IRI-2012 predictions for the ion temperature climatology at PFISR are shown in Figure 7 . The model overestimates the ion temperature at all the heights by $100-400 \mathrm{~K}$. The discrepancies are greater at higher altitudes. Chao et al. (2005), analyzing the ion temperature from the ROCSAT-1 satellite, pointed out that the IRI ion temperature at middle and low latitudes is too high in the topside ionosphere. Our results suggest that the overestimation of the IRI topside ion temperature extends to high latitudes.

\section{Summary and conclusions}

The present study focused on the ion temperature climatology observed in the polar region at the EISCAT Svalbard Radar, and in the auroral region at the Poker Flat Incoherent Scatter Radar during the International Polar Year from March 2007 to February 2008. The dependence of the high-latitude ion temperature climatology on the universal time, season, and geomagnetic activity was presented for both $\mathrm{F}$ region heights $(275$ and $350 \mathrm{~km})$ and an E region height $(125 \mathrm{~km})$. Detailed comparisons were made with a first-principles model, TIE-GCM, as well as with an empirical model, IRI-2012. The Weimer (2005) model was used to specify the highlatitude electric field of the TIE-GCM.

The main results of this study can be summarized as follows:

1. The ion temperature is generally higher at ESR than at PFISR by $\sim 200 \mathrm{~K}$ at all the heights considered (125, 275 , and $350 \mathrm{~km}$ ). The response of the ion temperature to geomagnetic activity is also greater at ESR.

2. The results of TIE-GCM experiments suggest that the pattern of the daily variation in the high-latitude ion temperature is primarily determined by ion-neutral frictional heating. The TIE-GCM results also suggest that the temperature difference between 275 and $350 \mathrm{~km}$ is largely due to electron heating.

3. Neither TIE-GCM nor IRI-2012 reproduces the strong daytime response to geomagnetic activity observed at ESR. This could be due to the lack of a heating mechanism in the dayside-cusp region in the models.

Acknowledgements. We are indebted to the director and staff of EISCAT for operating the facility and supplying the data. EISCAT is an international association supported by research organizations in China (CRIRP), Finland (SA), Japan (NIPR and STEL), Norway (NFR), Sweden (VR), and the United Kingdom (NERC). This work was supported by NERC Grant NE/K01207X/1. The editor thanks Ian McCrea and the anonymous referee for their assistance in evaluating this paper.

\section{References}

Allison, I., M. Beland, K. Alverson, R.E. Bell, D. Carlson, et al. The scope of science for the International Polar Year 2007-2008, WMO/TD-1364. World Meteorol. Organ., 117, Geneva, Switzerland, 79, 2007.

Bilitza, D. Models for ionospheric electron and ion temperature. In: V. Lincoln, R. Conkright, and K. Rawer, Editors. International 
Reference Ionosphere - IRI 79, Rep. UAG-82, World Data Cent. A for Sol. Terr. Phys, Boulder, Co, 7-10, 1981.

Bilitza, D. International reference ionosphere, National Space Science Data Center, Report 90-22, Greenbelt, Maryland, USA, 1990.

Bilitza, D. International Reference Ionosphere 2000. Radio Sci., 36, 261-275, 2001.

Bilitza, D., and B.W. Reinisch. International reference ionosphere 2007: improvements and new parameters. Space Res., 42, 599-609, 2008, DOI: 10.5047/eps.2011.05.023.

Bilitza, D., D. Altadill, Y. Zhang, C. Mertens, V. Truhlik, P. Richards, L.-A. McKinnell, and B. Reinisch. The International Reference Ionosphere 2012 - a model of international collaboration. J. Space Weather Space Clim., 4, A07, 2014, DOI: $10.1051 / \mathrm{swsc} / 2014004$.

Blelly, P.-L., D. Alcaydé, and A.P. van Eyken. A new analysis method for determining polar ionosphere and upper atmosphere characteristics from ESR data: illustration with IPY period. J. Geophys. Res., 115, A09322, 2010, DOI: $10.1029 / 2009 J A 014876$.

Chao, C.K., S.-Y. Su, and H.C. Yeh. Ion temperature variation observed by ROCSAT-1 satellite in the afternoon sector and its comparison with IRI-2001 model. Adv. Space Res., 37, 879-884, 2005.

Crowley, G., D.J. Knipp, K.A. Drake, J. Lei, E. Sutton, and H. Lühr. Thermospheric density enhancements in the dayside cusp region during strong BY conditions. Geophys. Res. Lett., 37, L07110, 2010, DOI: 10.1029/2009GL042143.

Deng, Y., A. Maute, A.D. Richmond, and R.G. Roble. Impact of electric field variability on Joule heating and thermospheric temperature and density. Geophys. Res. Lett., 36, L08105, 2009, DOI: 10.1029/2008GL036916.

Deng, Y., T.J. Fuller-Rowell, A.J. Ridley, D. Knipp, and R.E. Lopez. Theoretical study: influence of different energy sources on the cusp neutral density enhancement. J. Geophys. Res. [Space Phys.], 118, 2340-2349, 2013, DOI: 10.1002/jgra.50197.

Efron, B. Nonparametric estimates of standard error: the jackknife, the bootstrap, and other methods. Biometrika, 68 (3), 589-599, 1981.

Emmert, J.T., S.E. McDonald, D.P. Drob, R.R. Meier, J.L. Lean, and J.M. Picone. Attribution of interminima changes in the global thermosphere and ionosphere. J. Geophys. Res. [Space Phys.], 119, 6657-6688, 2014, DOI: 10.1002/2013JA019484.

Evans, J. Theory and practice of ionosphere study by Thomson scatter radar. Proc. IEEE, 57 (4), 496-530, 1969.

Finlay, C.C., S. Maus, C.D. Beggan, T.N. Bondar, A. Chambodut, et al. Ionospheric electrodynamics using magnetic apex coordinates. Geophys. J. Int., 183, 1216-1230, 2010.

Fujiwara, H., S. Nozawa, S. Maeda, Y. Ogawa, Y. Miyoshi, H. Jin, H. Shinagawa, and K. Terada. Polar cap ionosphere and thermosphere during the solar minimum period: EISCAT Svalbard radar observations and GCM simulations. Earth Planets Space, 64, 459-465, 2012, DOI: 10.5047/eps.2011.05.023.

Hagan, M.E., and J.M. Forbes. Migrating and nonmigrating diurnal tides in the middle and upper atmosphere excited by tropospheric latent heat release. J. Geophys. Res., 107 (D24), 4754, 2002, DOI: $10.1029 / 2001 J D 001236$.

Hagan, M.E., and J.M. Forbes. Migrating and nonmigrating semidiurnal tides in the upper atmosphere excited by tropospheric latent heat release. J. Geophys. Res., 108 (A2), 1062, 2003, DOI: 10.1029/2002JA009466.

King, J.H., and N.E. Papitashvili. Solar wind spatial scales in and comparisons of hourly Wind and ACE plasma and magnetic field data. J. Geophys. Res., 110, A02104, 2005,

DOI: $10.1029 / 2004 J A 010649$.

Kosch, J.M., and E. Nielsen. Coherent radar estimates of average high-latitude ionospheric Joule heating. J. Geophys. Res., 100, 12201-12215, 1995
Lehtinen, M.S., and A. Huuskonen. General incoherent scatter analysis and GUISDAP. J. Atmos. Terr. Phys., 58, 435-452, 1996.

Lei, J., R.G. Roble, W. Wang, B.A. Emery, and S.-R. Zhang. Electron temperature climatology at Millstone Hill and Arecibo. J. Geophys. Res., 112, A02302, 2007, DOI: $10.1029 / 2006 J A 012041$

Liu, H., H. Lühr, V. Henize, and W. Köhler. Global distribution of the thermospheric total mass density derived from CHAMP. J. Geophys. Res., 110, A04301, 2005, DOI: $10.1029 / 2004 J A 010741$

Lühr, H., M. Rother, W. Köhler, P. Ritter, and L. Grunwaldt. Thermospheric up-welling in the cusp region: evidence from CHAMP observations. Geophys. Res. Lett., 31, L06805, 2004, DOI: 10.1029/2003GL019314.

Miyoshi, Y., and H. Fujiwara. Day-to-day variations of migrating diurnal tide simulated by a GCM from the ground surface to the exobase. Geophys. Res. Lett., 30 (15), 1789, 2003, DOI: 10.1029/2003GL017695.

Ogawa, Y., S.C. Buchert, I. Häggström, M.T. Rietveld, R. Fujii, S. Nozawa, and H. Miyaoka. On the statistical relation between ion upflow and naturally enhanced ion-acoustic lines observed with the EISCAT Svalbard radar. J. Geophys. Res., 116, A03313, 2011, DOI: 10.1029/2010JA015827.

Oliver, W.L., J.M. Holt, S.-R. Zhang, and L.P. Goncharenko. Long-term trends in thermospheric neutral temperature and density above Millstone Hill. J. Geophys. Res., 119, 7940-7946, 2014, DOI: 10.1002/2014JA020311.

Picone, J.M., A.E. Hedin, D.P. Drob, and A.C. Aikin. NRLMSISE00 empirical model of the atmosphere: statistical comparisons and scientific issues. J. Geophys. Res., 107 (A12), 1468, 2002, DOI: $10.1029 / 2002 J A 009430$

Qian, L., A.G. Burns, B.A. Emery, B. Foster, G. Lu, et al. The NCAR TIE-GCM: a community model of the coupled thermosphere/ionosphere system. In: J. Huba, R. Schunk, G. Khazanov, eds. Modeling the Ionosphere-Thermosphere System, AGU Geophysical Monograph Series. John Wiley \& Sons, Ltd, Chichester, UK, 2014, DOI: 10.1002/9781118704417.

Remick, K.J. Baseline high-latitude ionospheric parameters and field-aligned ion motion. J. Geophys. Res., 111, A07311, 2006, DOI: $10.1029 / 2004 J A 010711$

Rentz, S., and H. Lühr. Climatology of the cusp-related thermospheric mass density anomaly, as derived from CHAMP observations. Ann. Geophys., 26, 2807-2823, 2008.

Richards, P.G., M.J. Nicolls, C.J. Heinselman, J.J. Sojka, J.M. Holt, and R.R. Meier. Measured and modeled ionospheric densities, temperatures, and winds during the international polar year. J. Geophys. Res. [Space Phys.], 114, A12317, 2009, DOI: $10.1029 / 2009 J A 014625$.

Richmond, A.D. Ionospheric electrodynamics using magnetic apex coordinates. J. Geomagn. Geoelectr., 47, 191-212, 1995.

Richmond, A.D., E.C. Ridley, and R.G. Roble. A thermosphere/ ionosphere general circulation model with coupled electrodynamics. Geophys. Res. Lett., 19, 601-604, 1992.

Russell, C.T., J.G. Luhmann, and L.K. Jian. How unprecedented a solar minimum? Rev. Geophys., 48, RG2004, 2010, DOI: $10.1029 / 2009 R G 000316$.

Sojka, J., R. Schunk, T. van Eyken, J. Kelly, C. Heinselman, and M. McCready. Ionospheric challenges of the International Polar Year. Eos Trans. $A G U, 88$ (15), 771, 2007, DOI: $10.1029 / 2007 \mathrm{EO} 150003$.

Sojka, J.J., R.L. McPherron, A.P. van Eyken, M.J. Nicolls, C.J. Heinselman, and J.D. Kelly. Observations of ionospheric heating during the passage of solar coronal hole fast streams. Geophys. Res. Lett., 36, L19105, 2009, DOI: 10.1029/2009GL039064.

Sojka, J.J., M. Nicolls, A. van Eyken, C. Heinselman, and D. Bilitza. $24 / 7$ solar minimum polar cap and auroral ion temperature observations. Adv. Space Res., 48, 1-11, 2011, DOI: 10.1016/j.asr.2011.03.005. 
Solomon, S.C., T.N. Woods, L.V. Didkovsky, J.T. Emmert, and L. Qian. Anomalously low solar extreme-ultraviolet irradiance and thermospheric density during solar minimum. Geophys. Res. Lett., 37, L16103, 2010, DOI: 10.1029/2010GL044468.

Tsurutani, B.T., W.D. Gonzalez, A.L.C. Gonzalez, F.L. Guarnieri, N. Gopalswamy, et al. Corotating solar wind streams and recurrent geomagnetic activity: a review. J. Geophys. Res., 111, A07S01, 2006, DOI: 10.1029/2005JA011273.

Vickers, H., M.J. Kosch, E. Sutton, Y. Ogawa, and C. La Hoz. Thermospheric atomic oxygen density estimates using the EISCAT Svalbard Radar. J. Geophys. Res. [Space Phys.], 118, 1319-1330, 2013, DOI: 10.1002/jgra.50169.

Vlasov, A., K. Kauristie, M. van de Kamp, J.-P. Luntama, and A. Pogoreltsev. A study of traveling ionospheric disturbances and atmospheric gravity waves using EISCAT Svalbard Radar IPY-data. Ann. Geophys., 29, 2101-2116, 2011, DOI: 10.5194/angeo-29-2101-2011.

Weimer, D.R. Improved ionospheric electrodynamic models and application to calculating Joule heating rates. J. Geophys. Res., 110, A05306, 2005, DOI: 10.1029/2004JA010884.

Yamazaki, Y., and A.D. Richmond. A theory of ionospheric response to upward-propagating tides: electrodynamic effects and tidal mixing effects. J. Geophys. Res. [Space Phys.], 118, 5891-5905, 2013, DOI: 10.1002/jgra.50487.

Yamazaki, Y., M.J. Kosch, and E.K. Sutton. North-south asymmetry of the high-latitude thermospheric density: IMF BY effect. Geophys. Res. Lett., 42, 225-232, 2015a,

DOI: $10.1002 / 2014 G L 062748$.
Yamazaki, Y., M.J. Kosch, and E. Sutton. A model of high-latitude thermospheric density. J. Geophys. Res. [Space Phys.], 120, 7903-7917, 2015b, DOI: 10.1002/2015JA021371.

Zettergren, M., J. Semeter, C. Heinselman, and M. Diaz. Incoherent scatter radar estimation of $\mathrm{F}$ region ionospheric composition during frictional heating events. J. Geophys. Res., 116, A01318, 2011, DOI: 10.1029/2010JA016035.

Zhang, S.-R., and J.M. Holt. Ionospheric plasma temperatures during 19762001 over Millstone Hill. J. Geophys. Res., 109, A11311, 2004, DOI: 10.1029/2004JA010709.

Zhang, S.-R., J.M. Holt, A.M. Zalucha, and C. Amory-Mazaudier. Midlatitude ionospheric plasma temperature climatology and empirical model based on Saint Santin incoherent scatter radar data from 1966 to 1987. Adv. Space Res., 33, 963-969, 2004.

Zhang, S.-R., J.M. Holt, D.K. Bilitza, T. van Eyken, M. McCready, C. Amory-Mazaudier, S. Fukao, and M. Sulzer. Multiple-site comparisons between models of incoherent scatter radar and IRI. Adv. Space Res., 39, 910-917, 2007.

Zhang, S.-R., J.M. Holt, A.P. van Eyken, C. Heinselman, and M. McCready. IPY observations of ionospheric yearly variations from high- to middle-latitude incoherent scatter radars. J. Geophys. Res., 115, A03303, 2010, DOI: 10.1029/2009JA014327.

Zhang, B., W. Lotko, O. Brambles, M. Wiltberger, W. Wang, P. Schmitt, and J. Lyon. Enhancement of thermospheric mass density by soft electron precipitation. Geophys. Res. Lett., 39, L20102, 2012, DOI: 10.1029/2012GL053519.

Cite this article as: Yamazaki Y, Kosch M, Ogawa Y \& Themens D. High-latitude ion temperature climatology during the International Polar Year 2007-2008. J. Space Weather Space Clim., 6, A35, 2016, DOI: 10.1051/swsc/2016029. 
Appendix: Calculations of $L_{\mathrm{ei}}$ and $L_{\mathrm{in}}$

The following are the calculation formulae for $L_{\mathrm{ei}}$ and $L_{\mathrm{in}}$ used in the TIE-GCM:

$$
\begin{gathered}
L_{\mathrm{ei}}=4.8 \times 10^{-7} \frac{\sqrt{N_{\mathrm{e}}}}{T_{\mathrm{e}} \sqrt{T_{\mathrm{e}}}}\left(\mathrm{N}_{\mathrm{O}^{+}}+0.5 \mathrm{~N}_{\mathrm{O}_{2}^{+}}+0.53 \mathrm{~N}_{\mathrm{NO}^{+}}\right) \\
L_{\mathrm{in}}=\mathrm{N}_{\mathrm{O}^{+}}\left(6.6 \times 10^{-14} \mathrm{~N}_{\mathrm{N}_{2}}+5.8 \times 10^{-14} \mathrm{~N}_{\mathrm{O}_{2}}+0.21 \times 10^{-14} \mathrm{~N}_{\mathrm{O}} \sqrt{2 T_{\mathrm{n}}}\right) \\
+\mathrm{N}_{\mathrm{NO}^{+}}\left(5.45 \times 10^{-14} \mathrm{~N}_{\mathrm{O}_{2}}+5.9 \times 10^{-14} \mathrm{~N}_{\mathrm{N}_{2}}+4.5 \times 10^{-14} \mathrm{~N}_{\mathrm{O}}\right) \\
+\mathrm{N}_{\mathrm{O}_{2}^{+}}\left(5.8 \times 10^{-14} \mathrm{~N}_{\mathrm{N}_{2}}+4.4 \times 10^{-14} \mathrm{~N}_{\mathrm{O}}+0.14 \times 10^{-14} \mathrm{~N}_{\mathrm{O}_{2}} \sqrt{T_{\mathrm{n}}}\right),
\end{gathered}
$$

where " $N_{X}$ " denotes the number density of " $X$ " in $\mathrm{cm}^{-3}$. 